\title{
ERRATUM
}

\section{Erratum to: Discussion: A New Method of Salvaging Breast Reconstruction After Breast Implant Using Negative-Pressure Wound Therapy and Instillation}

\author{
Francesco Ciancio $^{1} \cdot$ Domenico Parisi $^{2} \cdot$ Aurelio Portincasa $^{2} \cdot$ Alessandro Innocenti $^{3}$
}

Published online: 24 January 2017

(C) Springer Science+Business Media New York and International Society of Aesthetic Plastic Surgery 2017

\section{Erratum to: Aesth Plast Surg \\ DOI 10.1007/s00266-016-0734-6}

The first author's given name and family name were inverted. The correct order is Francesco Ciancio.

The original article was corrected.

The online version of the original article can be found under doi:10.1007/s00266-016-0734-6.

Alessandro Innocenti

innocentialessandro@alice.it

1 Department of Plastic and Reconstructive Surgery, University of Bari, Foggia, Italy

2 Department of Plastic and Reconstructive Surgery, University of Foggia, Foggia, Italy

3 Plastic and Reconstructive Microsurgery, Careggi University Hospital, Florence, Italy 